\title{
Medical Image of the Month: Large Complex Cerebral Arteriovenous Malformation
}

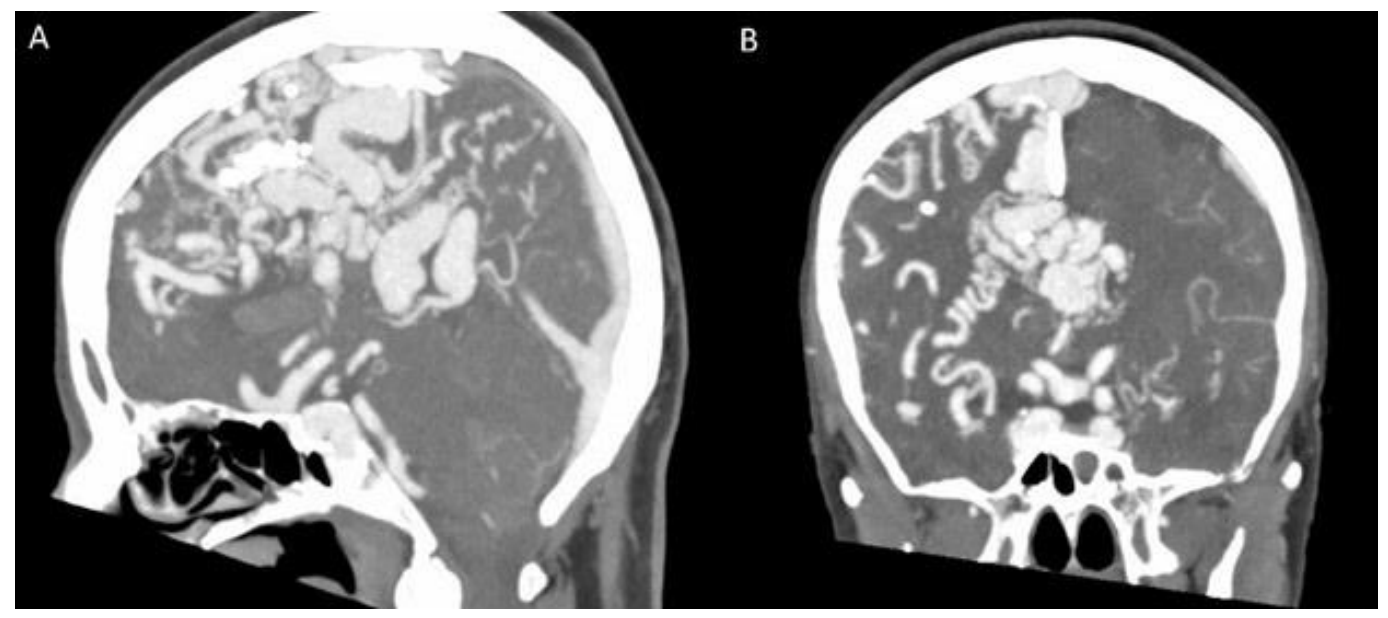

Figure 1. Computed tomography angiography of the head showing the large complex arteriovenous malformation near the midline of the brain. A: sagittal plane the malformation is fed predominantly by the anterior circulation more on the right and the left. B: coronal plane.

A 70-year-old woman with a history of hypertension presented with left-sided weakness, headache, nausea, and vomiting. She denied loss of consciousness or seizure activity. On examination, she had receptive aphasia. Pupils were equal, round and reactive. She had neck pain on flexion. Her left upper extremity was plegic. Computed tomography of the brain showed acute hemorrhage involving the right thalamus, extending into the ventricular system, and a midline mass. She underwent a computed tomography angiogram, which showed a large, complex arteriovenous malformation (AVM) with a dilated branch of the right suprasellar internal carotid artery feeding the AVM, which then drained into the vein of Galen and straight sinus (Figure 1). She was monitored in the intensive care unit without worsening neurological deficit. She was discharged to a rehabilitation facility, having had no intravascular or surgical intervention.

AVMs are intracranial vascular anomalies which occur in $0.1 \%$ of the population (1). Clinical presentations include intracranial hemorrhage, seizures, headaches and neurological deficits, with hemorrhage being the most common and significant manifestation (2). The gold standard imaging modality is conventional cerebral angiography (1). Treating an AVM is a challenging clinical problem, as the risk of treatment has to be weighed against the natural history of the condition. Treatment modalities include observation with medical management, surgical resection, stereotactic radiosurgery, and endovascular embolization $(1,2)$.

Vedhapriya Srinivasan MD, Piruthiviraj Natarajan MD, Reuben De Almeida, Safal Shetty MD, and Kulothungan Gunasekaran MD.

Bridgeport Hospital

Yale New Haven Health

New Haven, CT USA 


\section{References}

1. Ajiboye N, Chalouhi N, Starke RM, Zanaty M, Bell R. Cerebral arteriovenous malformations: evaluation and management. ScientificWorldJournal 2014;2014:649036. [CrossRef] [PubMed]

2. Geibprasert S, Pongpech S, Jiarakongmun P, Shroff MM, Armstrong DC, Krings T. Radiologic assessment of brain arteriovenous malformations: what clinicians need to know. RadioGraphics. 2010;30:483-501. [CrossRef] [PubMed] 